\title{
A RELAÇão ENTRE O PRINCÍPIO DA NÃO MALEFICÊNCIA E O Utilitarismo na ética de Peter Singer
}

\author{
[THE RELATION BETWEEN THE PRINCIPLE OF NON-MALEFICENCE AND UTILITARISM IN PETER \\ SINGER's ETHICS]
}

\author{
Wesley Felipe de Oliveira * \\ Universidade Estadual de Londrina, Brasil \\ Camila Dutra Pereira ** \\ Universidade Estadual de Londrina, Brasil
}

RESUMo: Este artigo analisa a interpretação de Renzo Llorente de que a obra Libertação Animal, de Peter Singer, não tem sua estrutura moral baseada no utilitarismo, mas no princípio da não-maleficência. $O$ artigo analisa criticamente essa interpretação e busca responder os problemas levantados. Consideramos de que maneira essa interpretação não se sustenta quando a ética de Singer é compreendida em seu conjunto e não apenas a partir de uma única obra. Porém, defendemos, neste artigo, apesar de a proposta ética de Libertação Animal tenha aspectos do princípio da não-maleficência, a obra se mantém utilitarista na medida que o princípio de não causar danos se fundamenta e se justifica por razões utilitaristas.

Palavras-chave: ética; utilitarismo; nãomaleficência; animais
ABSTRACT: This article analyzes Renzo Llorente's interpretation that Peter Singer's work Animal Liberation does not have a moral structure based on utilitarianism, but on the principle of non-maleficence. The article critically analyzes this interpretation and seeks to answer the problems raised. We consider how this interpretation does not hold when Singer's ethics is understood as a whole and not just from a single work. However, we defend, in this article, although the Animal Liberation ethical proposal has aspects of the principle of non-maleficence, the work remains utilitarian inasmuch as the principle of not causing harm is based and justified for utilitarian reasons.

KEYwORDs: ethics; utilitarism; nonmaleficence; animals

\section{INTRODUÇÃO}

presente artigo tem como objetivo discutir a interpretação de Renzo Llorente acerca da obra Libertação Animal, de Peter Singer. No artigo The Moral Framework of Peter Singer's Animal Liberation: an alternative to utilitarianism, Llorente, defende que os argumentos que constituem a estrutura moral desta obra, não podem ser devidamente interpretados a partir do utilitarismo. Antes, sua estrutura moral e conceitual deve ser lida a partir do princípio da não-maleficência, resumida pela sentença não causar danos.

$\mathrm{Na}$ análise dessa interpretação, nosso artigo investigará as razões que, segundo Llorente, conduzem os leitores a interpretarem, segundo ele de maneira equivocada, os argumentos do livro de Singer a partir de um ponto de vista utilitarista. Ao analisarmos

* Doutor em Filosofia na área de Ética e Filosofia Politica pela Universidade Federal de Santa Catarina (UFSC). Pós-Doutorando na Universidade Estadual de Londrina - UEL. E-mail: wesley.filosofia@hotmail.com.** Mestranda em Filosofia na Universidade Estadual de Londrina - UEL. Graduada e Especialista em Direito pela Pontifícia Universidade Católica do Paraná PUCPR.E-mail: dcamila@gmail.com 
criticamente essas razões, buscaremos responder as questões levantadas por Llorente, demonstrando que embora Libertação Animal possa conter alguns aspectos do princípio da não-maleficência, isso não anula o caráter utilitarista que a fundamenta.

Analisaremos que embora Singer não mencione e tampouco conceitue o utilitarismo em Libertação Animal, o mesmo se dá em relação ao conceito da nãomaleficência que Llorente atribui à obra. A ausência de conceitos utilitaristas rigorosamente definidos na obra (que não é destinada a um público acadêmico e especialista em filosofia) não impede que encontremos implícitos nela tais princípios. Por fim, buscaremos demonstrar que o princípio da não-maleficência é parte do princípio utilitarista. Se assim for, interpretar a obra como baseada na não-maleficência não a descaracteriza como utilitarista. Além do mais, levaremos em conta que as semelhanças que Libertação Animal mantém com a obra Ética Prática, principalmente em seu terceiro capítulo, conferem mais evidências textuais e argumentativas significativas para que a estrutura moral de Libertação Animal seja, de fato, considerada como utilitarista. Compreendemos que o pensamento filosófico de um autor não deve ser analisado apenas a partir de uma única obra específica, mas sim no seu conjunto de livros e artigos em torno da questão que ele discute.

1.Razões para o utilitarismo e para o princípio da não-maleficência em

\section{Libertação Animal}

De acordo com Llorente, o que frequentemente ocorre na leitura de Libertação Animal é uma interpretação equivocada, não apenas por leitores que não estão envolvidos academicamente com a pesquisa filosófica, mas também pelos principais filósofos e acadêmicos que têm debatido a ética em relação aos animais. $\mathrm{O}$ equívoco interpretativo, segundo Llorente se resume em considerar que a obra possui uma estrutura moral utilitarista.

O erro mais comum entre os filósofos profissionais consiste, sem dúvida, na crença de que o argumento moral defendido em Libertação Animal é baseado no utilitarismo, ou - o que em efeito significa a mesma coisa - a tendência em analisar o livro como se a base normativa fosse utilitarista, quando na realidade a visão defendida em Libertação Animal é derivada, no fundo, tanto do princípio da não-maleficência, isto é, "não causar dano," quanto do princípio da igual consideração de interesses (LLORENTE, 2009, p. 62, tradução nossa).

Por certo, a obra oferece fortes indicativos para interpretá-la segundo a perspectiva utilitarista, a começar pelas citações que Singer faz de filósofos evidentemente utilitaristas, como Jeremy Bentham e Henry Sidwik. Mas, por outro lado, observa Llorente, apesar das menções a esses dois autores, é notável que os termos utilitarismo, e até mesmo utilidade, não aparecerem ao longo das páginas de Libertação Animal. Porém, devemos levar em conta que isso, possivelmente, venha a ser antes uma preocupação e opção de escrita de Singer. O autor não busca dispor neste livro termos técnicos e acadêmicos, uma vez que ele tem em vista escrever justamente a um público não especializado. Isso fica claro nos prefácios de suas várias edições. $\mathrm{Na}$ de 1990, por exemplo, Singer observa:

Decidi não responder a todos os pontos levantas pelos filósofos sobre os argumentos éticos desse livro. Isso alteraria a natureza do próprio livro, transformando-o em um trabalho acadêmico, interessante para meus colegas de profissão, porém enfadonho para o leitor comum. Em vez disso, indiquei, em locais apropriados no texto, alguns outros escritos, onde minhas respostas a certas objeções podem ser encontradas (SINGER, 2004, p. xii).

Tanto essas respostas quanto o aprofundamento filosófico de várias questões 
podem ser encontradas principalmente em Ética Prática, publicado originalmente quatro anos depois de Libertação Animal. Mas, a despeito disso, Llorente considera que o que pesa determinantemente é o fato de o próprio Singer, ao discutir ligeiramente a estrutura normativa no primeiro capítulo, intitulado: "Todos os animais são iguais, ou por que o princípio ético no qual se baseia a igualdade humana exige que se estenda igual consideração também aos animais", tornar evidente que o seu argumento procede de uma determinada concepção que é característica do princípio da não-maleficência, ao escrever que "as conclusões defendidas nesse livro partem do princípio da minimização apenas do sofrimento" (SINGER, 2004, p. 25, grifo nosso). ${ }^{1}$

Possivelmente, outra questão que tenha motivado Llorente a fazer tal interpretação não-utilitarista, seja uma resposta que o próprio Singer oferece às objeções a respeito da orientação normativa de sua obra feitas por Robert Solomon no capítulo The Expanding Circle: Compassion and the Liberation Ethic, que compõe o livro Singer and His Critics. Para Solomon (1999), os argumentos de Singer recorrem a sentimentos muito vagos e à compaixão e não a uma racionalidade moral, valendo-se, para isso, até mesmo do uso de descrições e imagens fotográficas de animais em sofrimento que causem um impacto emocional. Ao responder essa e outras críticas e observações feitas por Solomon, destaca-se, para o presente artigo, a afirmação categórica de Singer de que "o texto de Libertação Animal não é utilitarista" (SINGER 1999 , p. 283, tradução nossa), pois a sua preocupação é "especialmente destinada a atrair os leitores que estavam preocupados sobre a igualdade, justiça, equidade, independentemente da natureza precisa de seu compromisso" (SINGER, 1999, p. 283, tradução nossa). Isso, como destacamos, Singer já havia expressado em sua obra.

Mas, mesmo que sua preocupação não era a de escrever uma obra estritamente técnica, podemos, ainda assim, nos perguntar por quais razões se persiste uma interpretação predominante de que Libertação Animal seria um texto de caráter utilitarista, uma vez que o próprio Singer declarou que tal corrente filosófica não faz parte desta obra em específico. Llorente pontua algumas razões para isso.

Há, como ressaltado anteriormente, algumas menções aos filósofos utilitaristas que Singer usa para embasar seus argumentos. Além disso, não se pode ignorar o fato do autor defender em diversos artigos, livros e capítulos de livros que se seguiram de Libertação Animal, que sua posição ética é, de fato, o utilitarismo, mais precisamente o utilitarismo de preferências, como o faz principalmente em Ética Prática ${ }^{2}$. Além do mais, os diversos outros temas por ele investigados, como aborto, eutanásia, a morte de animais, meio ambiente etc., têm como pano de fundo teórico as posições utilitaristas. Soma-se a isso o fato de Singer admitir que as razões pelas quais ele é vegetariano se devem ao utilitarismo ${ }^{3}$. É justamente desse modo que ele inicia seu artigo Utilitarianism and Vegetarianism, afirmando:

Eu sou um utilitarista. Eu também sou um vegetariano. Sou vegetariano porque sou utilitarista. Acredito que aplicando o princípio da utilidade à nossa presente situação - especialmente os métodos hoje usados para criar animais para alimentos e a variedade de alimentos disponível para nós - leva-nos a conclusão de que devemos ser vegetarianos (SINGER, 1980, p. 325, tradução nossa).

Levando em conta o conjunto dessas considerações torna-se inevitável vincular a obra Libertação Animal, na qual se advoga em defesa do vegetarianismo, com a perspectiva do utilitarismo presente de maneira majoritária nos trabalhos de Singer. Além disso, conforme ele assume, a ética utilitarista é a base moral em que ele fundamenta a sua escolha em não usar animais na alimentação.

Outra razão colocada por Llorente se deve às características presentes nas 
diversas descrições de que Singer faz uso e na qual são permeadas de termos essencialmente utilitaristas. Por exemplo, ao lermos: "não há justificativa moral para considerar que a dor (ou o prazer) que os animais sentem seja menos importante que a mesma intensidade de dor (ou prazer) sentida por seres humanos" (SINGER, 2004, p. 17, grifo nosso), somos levados a interpretar o texto com uma base utilitarista. Isso se deve porque ele introduz considerações que rementem diretamente aos conceitos benthanianos como quantidade ou intensidade da dor e do prazer, o que está diretamente associado com o utilitarismo, mais precisamente em sua versão clássica ou hedonista ${ }^{4}$. Verifica-se isso, também, na citação a seguir:

Se dermos uma palmada forte na anca de um cavalo, com a mão aberta, o cavalo poderá assustar-se, mas provavelmente sentira pouca dor. Seu couro é espesso o bastante para protegê-lo contra um simples tapa. Entretanto, se dermos um tapa em um bebê com a mesma intensidade, ele chorará e provavelmente sentirá dor, pois sua pele é mais sensível. Portanto, é pior dar uma palmada num bebê do que num cavalo, se ambas as palmadas forem dadas com igual força. Mas, deve haver algum tipo de pancada - não sei exatamente qual seria, mas talvez uma pancada com um pau pesado - que provocaria no cavalo tanta dor quanto a causada em um bebê com uma palmada (SINGER, 2004, p. 18). ${ }^{5}$

Exemplo como o acima mencionado trata acerca da igual consideração dos interesses, mais precisamente do interesse em não sentir dor, existente de acordo com Singer em todos os seres sencientes, ou seja, dotados da capacidade de sentir dor e sofrimento. Tal argumentação presente no exemplo nos inclina a pensarmos a partir de categorias utilitaristas devido à importância que o princípio da igualdade possui na tradição utilitarista, expressa na máxima de Bentham, segundo a qual "cada um conta por um e ninguém como mais de um" (BENTHAN apud SINGER, 2004, p. 06), citada por Singer em Libertação Animal e repetida posteriormente em Ética Prática, uma obra que, por sua vez, é claramente utilitarista ${ }^{6}$. Mais emblemático ainda é a clássica referência que Singer faz à citação de Bentham que fundamenta a capacidade de ter um interesse e um direito a igual consideração não na capacidade de raciocínio ou linguagem, mas na capacidade de sentir e sofrimento. ${ }^{7}$

Segundo Llorente, o próprio Singer confunde seus leitores, pois os argumentos desenvolvidos no posterior artigo, Utilitarianism and Vegetarianism, não trazem claramente uma distinção em relação aos que estão em Libertação Animal. Isso, segundo Llorente, acaba por dar a impressão de que ambos os escritos sejam complementares ou que esta obra também é utilitarista.

Finalmente, é importante notar que Singer é responsável por parte dessa fundamental má interpretação de Libertação Animal. Isso é verdadeiro por algumas razões. De início, no que é provavelmente sua declaração mais extensiva sobre o vegetarianismo pela perspectiva utilitarista (publicado cinco anos após a primeira edição de Libertação Animal), Singer falha em distinguir o argumento utilitarista para o vegetarianismo dos argumentos presentes em Libertação Animal, e isso, com efeito, cria a impressão de que o último é baseado em razões utilitaristas (LLORENTE, 2009, p. 64, tradução nossa).

Como temos observado, muitas das proposições centrais que são expostas em Libertação Animal se aproximam de características centrais do utilitarismo. Para Llorente, a afirmação de que as conclusões defendidas na obra "partem do princípio da minimização apenas do sofrimento" (SINGER, 2004, p. 25) deve ser tomada muito mais precisamente como "uma afirmação do princípio da não-maleficência" (LLORENTE, p. 65.). Apesar disso, observa Llorente: 
[...] Devo reconhecer, no entanto, que a frase se presta plenamente a uma interpretação distintamente utilitarista, pois usar a locução "minimizar o sofrimento" é valer-se de uma expressão que indica ao utilitarismo clássico. De fato, Karl Popper propôs essas palavras "minimizar sofrimento" como o lema do chamado utilitarismo negativo (LLORENTE, 2009, p. 65, tradução nossa).

Tal indicação se deve, obviamente, pelo fato de a minimização da dor (infelicidade) e a maximização do prazer (felicidade) serem noções fortemente utilitaristas. Bentham, por exemplo, considera que "uma coisa promove o interesse de um indivíduo, quando tende a aumentar a soma total dos seus prazeres, ou então, o que vale afirmar o mesmo, quando tende a diminuir a soma total das suas dores", (BENTHAM, 1984, p. 04) isto é, evitando-lhe os danos para diminuir ou evitar o sofrimento. Stuart Mill, por sua vez, buscando elaborar uma forma mais sofisticada do princípio do utilitarismo, enuncia-o como sendo:

O credo que aceita a utilidade, ou o Princípio da Maior Felicidade, como fundamento da moralidade, defende que as ações estão certas na medida em que tendem a promover a felicidade, erradas na medida em que tendem a produzir' o reverso da felicidade. Por felicidade, entende-se o prazer e a ausência de dor; por infelicidade, a dor e a privação de prazer. (MILL, 2005, p. 22).

Nesse sentido, podemos compreender que se a preocupação em agir de modo a não causar dano resulta justamente em evitar que um ser venha sofrer, e não impedindoo, portanto, de desfrutar do prazer e da felicidade, há, então, uma proximidade conceitual do princípio da não-maleficência com o utilitarismo. Além disso, o valor moral de não causar dano se deriva, em boa medida, de análise consequencialista. Se esse for o caso, não haveria equivoco em ler Libertação Animal como uma obra utilitarista, no mínimo uma obra utilitarista negativa, pois não sentir dor é uma forma de se produzir felicidade e bem-estar, o que implica, portanto, em uma escolha moral que se baseia no princípio utilitarista.

Llorente observa também que muitas das respostas de Singer aos seus críticos oferecem aos leitores razões para adotar uma interpretação utilitarista de Libertação Animal. Isto se dá de dois modos: i) nas tentativas de responder as objeções dirigidas a sua obra, "Singer tem se dado ao trabalho de responder as críticas que só fazem sentido na suposição de que o livro é um exercício de filosofia utilitarista," (LLORENTE, 2009 , p. 65) e, ii) por Singer frequentemente ter recorrido "aos raciocínios utilitaristas em seus esforços para refutar as várias críticas levantadas contra Libertação Animal." (LLORENTE, 2009, p. 65).

Além dessas questões, Llorente aponta cinco pontos que são relevantes por refletirem uma incoerência teórica na interpretação de Singer, mas que só existem na medida em que Libertação Animal for interpretada como um texto utilitarista. Segundo Llorente, a partir do instante em que tais argumentos passarem a serem lidos "como um trabalho no qual a inspiração básica normativa é o princípio da não-maleficência, não existem tais inconsistências" (LLORENTE, 2009, p. 65, tradução nossa). As cinco questões a que ele se refere, portanto, são: i) o uso da violência para a defesa animal; ii) o argumento da substituição; iii) a justificação ética para o vegetarianismo; iv) a conveniência de intervenções humanas na natureza para prevenir o dano que alguns animais infligem aos outros, e, v) a atitude de Singer para o especismo (LLORENTE, 2009).

Para Llorente, o utilitarismo pode ser interpretado a partir de quatro pontos característicos que o define: (i) é uma doutrina consequencialista, ou seja, o que é relevante na avaliação moral das ações são as consequências; (ii) há apenas um 
conjunto unificado de consequência que importa ser levado em consideração: o prazer, felicidade, bem-estar, satisfação das preferências etc., sendo esse conjunto de estados um bem intrínseco; (iii) o princípio de maximização desse bem intrínseco; e (iv) a felicidade, o prazer, bem-estar de cada pessoa, ou qualquer outro elemento desse conjunto de bem intrínseco, é moralmente importante e deve ser levado igualmente em consideração.

É com base nessa leitura do utilitarismo que Llorente se questiona: "qual é, então, na sua estrutura mais geral, o argumento básico a partir do qual Singer deriva todas as suas prescrições e as conclusões mais importantes de Libertação Animal?" (LLORENTE, 2009, p. 66). O autor acredita que as posições apresentadas por Singer não conferem ao seu texto um caráter utilitarista segundo os quatro pontos anteriores, mas antes, seus fundamentos se aproximam muito mais do princípio da nãomaleficência aplicado aos animais conforme a estrutura exposta por Colin McGinn (1999) em seu artigo Our Dutis to Animals and the Poor:

1) É moralmente errado causar sofrimento e morte nos animais desnecessariamente; 2) Nós causamos o sofrimento e a morte de animais desnecessariamente. Sendo assim: 3) O que fazemos aos animais é moralmente errado (MCGINN, 1999, p. 151, tradução nossa).

A partir disso, pode-se inferir que transformar animais em alimentos ou roupa, caçá-los, praticar a vivissecção em seus corpos etc., são atos que seguramente infligem algum tipo de dor e sofrimento, isto é, algum tipo de dano. Mas, segundo McGinn as premissas desse argumento e a sua conclusão não são necessariamente utilitaristas, porque, de acordo com o autor:

Não é necessário derivar o argumento de alguma forma geral do utilitarismo. Não precisamos tomar a primeira premissa para depender de algum princípio geral, como é o nosso dever de maximizar o prazer e diminuir a dor. Tudo o que o argumento exige é que nós não devemos causar o sofrimento e a morte desnecessariamente a um animal; isso não implica que temos um dever de sair pelo mundo e prevenir o máximo possível o sofrimento animal. O argumento é claro, considera que o sofrimento animal é uma coisa ruim, mas não nos compromete com o princípio de que devemos fazer tudo o que podemos para prevenir qualquer sofrimento animal em qualquer lugar (McGINN, 1999, 152).

Segundo entende Llorente, essa afirmativa de McGinn esclarece de que modo o argumento de Libertação Animal "não inclui qualquer imperativo de maximização (nem, aliás, é consequencialista) e por esta razão apenas não deveria ser considerado de natureza utilitária" (LLORENTE, 2009, p. 67, tradução nossa). Llorente acrescenta ainda que a primeira premissa do argumento "constitui uma variedade do princípio da não-maleficência, junto com o princípio da igual consideração de interesses (por isso a extensão abrange os animais)" (LLORENTE, 2009, p. 67, tradução nossa). O que é mais fundamental, no entanto, é que:

Mesmo se Libertação Animal pudesse ser lida como um argumento utilitarista, ele não deveria ser lido dessa forma, Singer evidentemente não queria que ele fosse lido dessa forma, e isso se mostra muito mais coerente e defensível se não for lido dessa maneira (LLORENTE, 2009, p. 67).

A seguir, analisaremos mais detalhadamente as cinco questões inconsistentes anteriormente mencionadas. Ao fazermos isso, buscaremos responder aos problemas mencionados. 


\section{O USO DA VIOLÊNCIA DA DEFESA ANIMAL}

A primeira destas questões diz respeito ao uso da violência para retirar os animais de situações nas quais há sofrimento e dano. A questão é colocada por Llorente do seguinte modo: "Podemos justificar o recurso à violência contra seres humanos a fim de obter a libertação de alguns animais, ou talvez até mesmo para promover os objetivos da libertação animal em geral?" (LLORENTE, 2009, p. 67, tradução nossa). Llorente analisa esse problema de duas maneiras.

Primeiramente, critica a desaprovação moral de Singer ao uso de ações violentas praticadas por alguns movimentos de defesa dos direitos e da libertação dos animais. Em resposta às ações desses grupos, Singer dedicou especialmente o final do prefácio da segunda edição (1990) de Libertação Animal, enunciando que:

Seria um erro trágico se mesmo um pequeno segmento do movimento de Libertação tentasse alcançar seus objetivos ferindo as pessoas. Alguns acreditam que pessoas que fazem os animais sofrer merecem que também se os façam sofrer. Não acredito em vingança; mas mesmo que acreditasse, seria um desvio prejudicial à nossa tarefa de fazer cessar o sofrimento. Violência só pode gerar violência - um clichê, mas cuja trágica verdade pode ser vista em meia dúzia de conflitos ao redor do mundo. A força da causa da Libertação Animal reside em seu compromisso ético (SINGER, 2004, p. xiv-xv).

Considerações dessa natureza, ainda que tenham uma justificativa moral (princípio da não-violência), contém, segundo Llorente, aspectos de uma perspectiva especista e uma incoerência na aplicação do princípio da igual consideração. $\mathrm{O}$ interesse dos animais em não sofrer não é igualmente levado em consideração quando comparado ao interesse de seres humanos em situação semelhante. A posição de Singer sobre esta questão acaba por negar certas medidas ou ações que a maioria das pessoas estaria inclinada a aprovar moralmente se as vitimas do sofrimento em questão fossem, no entanto, humanos ao invés de animais.

Se pensarmos em situações nas quais seres humanos estão sujeitos às experiências danosas e dolorosas ou mantidos em algum tipo de confinamento forçado que se assemelhe, de algum modo, com as características das modernas fazendas industriais, quase todos aceitariam, afirma Llorente, que o uso de medidas violentas fosse empregadas contra outros seres humanos a fim de libertar as vítimas de tais situações de sofrimento. ${ }^{8}$

$\mathrm{Na}$ prática, é isso o que ocorre em casos de terrorismo e sequestro, quando a única opção para se evitar um dano e um sofrimento maior é o recurso à intervenção violenta. Mas, essa diferença na posição de Singer em rejeitar atos de violência contra humanos para a libertação de animais, pode "ser interpretada como um vestígio de, ou pelo menos uma importante concessão ao especismo" (LLORENTE, 2009, p. 68, tradução nossa). Nesse sentido, o autor entende que seria coerente se Singer argumentasse em favor de uma ou outra opção: ou rejeitasse ou aceitasse de maneira absoluta atos de violência para libertar membros de ambas as espécies.

Em Ética Prática (2018), Singer parece ter refinado esse seu posicionamento sobre o uso da violência em premissas utilitaristas. Novamente, propondo um raciocínio utilitário que percorre toda a sua obra, Singer reforça sua posição de que a violência contra seres humanos para libertar seres humanos é justificável desde que "o objetivo seja impedir uma violência muito maior, que não haja outra maneira de deter essa violência mais disseminada e que o sucesso de um único ato de violência seja extremamente provável" (SINGER, 2018, p. 406).

Mas, notemos que a sua análise consequencialista se mantém também para 
justificar a negação do uso da violência. Singer observa que a oposição pode ser feita com base numa regra absoluta ou numa avaliação das consequências. Quanto à primeira, no entanto, pondera-se que "se são bem fundadas as objeções à distinção entre atos e omissões [...] aqueles que não recorrem à violência para impedir uma violência maior têm de assumir a responsabilidade pela violência que poderiam ter evitado" (SINGER, 2018, p. 401). Desse modo, a rejeição a tal distinção estabelece uma diferença crucial para a discussão da violência, possibilitando um argumento plausível em sua defesa: "Seria unilateral afirmar que a revolução violenta seja sempre absolutamente errada, sem levarmos em consideração os males que os revolucionários estão tentando extirpar" (SINGER, 2018, p. 403). Portanto, a aceitação ou rejeição de Singer ao uso de violência está baseada em premissas utilitaristas consequencialistas que devem nortear a tomada de decisão. Isso faz com que cada situação seja analisada em sua particularidade.

A segunda crítica de Llorente neste aspecto diz respeito ao fato de que, mais uma vez, em Libertação Animal: "Singer omite completamente qualquer referência à justificação utilitária para o uso da violência em casos que, sendo mais ou menos análoga à exploração e o abuso de animais, envolvem seres humanos" (LLORENTE, p. 68, tradução nossa). Mas, não parece ser esse o caso. Como destacamos, Singer faz uso de cálculos notoriamente utilitaristas consequencialistas para justificar o uso de violência em casos muito específicos. Se imaginarmos situações como as anteriormente mencionadas de atos de terrorismo e sequestro, existirão razões, de caráter essencialmente utilitarista, que sancionarão atos de violência, como a morte dos (poucos) terroristas ou sequestradores em virtude dos benefícios gerados, que se resultam em salvar a vida de um número maior de pessoas mantidas como reféns de um ato violento de terror. Essa é a posição caracteristicamente utilitarista de Singer. Comparando sua análise deste assunto com o que é feito em outras obras, percebe-se a semelhança estreita entre os argumentos, o que justifica considerar que as justificativas em Libertação Animal se baseiam em proposições utilitaristas.

Mas, para Llorente, se a conclusão presente em Libertação Animal fosse deduzida de premissas utilitaristas, os comentários de Singer contrários ao uso da violência para libertar animais permanecem inconsistentes e absurdas, e oferecem ainda uma concessão para o especismo. A partir disto, Llorente considera que:

O fato é que o argumento de Singer não é um argumento utilitarista, ou no mínimo não precisa ser interpretado como tal. Antes, ele procede da premissa formulada por McGinn: 'é moralmente errado causar o sofrimento e morte de animais desnecessariamente'. Se levarmos isso em consideração, não há inconsistência entre a estrutura normativa de Libertação Animal e a posição de Singer sobre a violência. (LLORENTE, 2009, p. 69, tradução nossa).

Porém, há de se levar em conta o aspecto prático que uma literal libertação dos animais, abrupta e violenta (contra humanos), esbarraria em outro problema que Llorente ignora e que Singer já havia levantado em Libertação Animal:

Problema mais grave é que a literal libertação de animais de laboratório e granjas industriais pode ser tão-somente um gesto simbólico, pois os pesquisadores simplesmente encomendarão novas levas de animais e, além disso, quem pode encontrar abrigo para mil porcos ou 100 mil frangos de uma granja industrial? (SINGER, 2004, p. xiii).

Há, portanto, significativas diferenças entre os resultados (ou consequências) de ambas os tipos de ações que fundamentam a perspectiva de Singer em não se recorrer à violência que se apresentam como cálculo utilitarista consequencialista. É notável, 
como temos destacado, que no prefácio (e ao longo da obra) Singer omite referências técnicas ao utilitarismo. Mas, ao analisar situações em que experiências em animais pudessem salvar milhões de vidas, Singer faz a seguinte comparação e observação acerca da tortura de seres humanos inocentes se esta fosse a única maneira de se salvar vidas.

A tortura de um ser humano é quase sempre errada, mas não é absolutamente errada. Se a tortura fosse a única maneira de se descobrir a localização de uma bomba nuclear escondida em algum porão de Nova York, programada para explodir em uma hora, a tortura se justificaria. Analogamente, se uma simples experiência pudesse curar uma doença como a leucemia, essa experiência seria justificável (SINGER, 2004, p. 94). ${ }^{9}$

Ainda que Llorente não mencione em seu artigo a consideração acima, podemos notar que ela reforça a ideia de que a estrutura moral de Libertação Animal é de fato utilitarista, pois o utilitarismo sustenta que, em situações excepcionais, se torture um único indivíduo a fim de, por exemplo, por meio desse ato se descobrir a localização de uma bomba e salvar a vida de muitas pessoas em um edifício. Se todo o sofrimento causado pelo desabamento das torres gêmeas em 11 de setembro que vitimaram três mil pessoas fosse possível de ser evitado pela violência cometida contra os terroristas, um utilitarista não teria objeções.

Para Llorente, as considerações de Singer em relação ao uso da violência não colocam problemas para a consistência de sua posição moral se Libertação Animal deixar de ser interpretada como um trabalho utilitarista. Contudo, considerando o posicionamento expresso pelo autor na obra Ética Prática como uma continuidade e um aprofundamento de sua teoria, verificamos que ele não se opõe ao uso da violência para salvar humanos ou animais, condicionando-a ao atendimento de requisitos bastante específicos: "se essa ação seria realmente justificável de um ponto de vista consequencialista dependeria dos detalhes da situação concreta" (SINGER, 2018, p. 406), o que pressupõe juntamente um cálculo de maximização de utilidade e minimização do sofrimento.

Mas, se Singer adota o princípio de não causar danos, ele deveria recusar em absoluto tanto os atos de violência contra humanos (caso dos terroristas e sequestradores) quanto o caso de alguns experimentos excepcionais que poderiam vir a ser realizados em animais (e até mesmo em alguns humanos em certas condições e contextos muito específicos e até mesmo raros). Esse, no entanto, não parece ser, a partir do que analisamos, o caso de Singer. Sua posição admite, em alguns casos, causar danos para evitar males maiores, uma posição claramente utilitarista para resolver dilemas morais, que, por sua natureza, nunca tem uma resposta completamente satisfatória no sentido de não causar nenhum tipo de dano ou prejuízo. Se Singer negar em absoluto o recurso à violência, ele faria isso em outra base moral que não o utilitarismo.

Apesar de Singer não rejeitar o uso da violência para salvar humanos, ele só a considera justificável em casos bastante singulares, partindo sempre da perspectiva consequencialista para avaliá-los. Se sua posição fosse especista, contudo, a rejeição ao uso da violência para salvar animais se daria tão somente em razão da espécie, o que não é verdadeiro na medida em que Singer atribui maior consideração ao sofrimento humano apenas quando este é maior devido às circunstâncias. Em um cálculo consequencialista, a violência contra a propriedade, por exemplo, como ocorre em ataques aos laboratórios e equipamentos, resulta, na prática, apenas numa nova aquisição de equipamentos e animais, tendo, portanto, um efeito nulo. 


\section{O Argumento da Substituição.}

O chamado argumento da substituição é um dos problemas centrais não apenas em Libertação Animal, mas também em Ética Prática. Talvez seja o argumento que mais tenha passado por revisões e reformulações ao longo na trajetória filosófica de Singer. Ainda na última edição desta última obra, Singer reconhece não estar satisfeito com sua posição em relação a esse argumento ${ }^{10}$.

A ideia central defendida pelo argumento da substituição considera que os animais criados para serem destinados ao consumo não existiriam se não fosse o nosso interesse em usá-los na alimentação. A razão pela qual eles existem é justamente porque são criados para serem consumidos. Levando em conta que o prazer e a satisfação são coisas valiosas, se todos fossem vegetarianos ou veganos muitos animais, como bois, vacas, galinhas, ovelhas etc., não existiriam e, assim, não teriam o benefício da existência e jamais desfrutariam o prazer da vida. De um ponto de vista utilitarista, ao se trazer animais para a existência se estaria maximizando o prazer, e, sendo isso algo valioso, não seria moralmente errado trazê-los à existência e usá-los, desde que: i) esses animais desfrutem de uma vida satisfatória, isto é, com prazer; ii) que sejam mortos de uma forma rápida, indolor e inconsciente, de modo a evitar que sofram também de medo ou stress, e, iii) os demais animais próximos ao animal morto não sofram em razão da separação e abate do outro animal.

Uma primeira observação, no entanto, que pode ser analisada acerca deste argumento é a sua praticidade e viabilidade. A carne de animais produzida de acordo com os critérios e condições sustentados pelo argumento da substituição refere-se a uma pequena parte da quantidade total de carnes consumidas na sociedade industrial.

Além disso, a principal condição que o argumento da substituição coloca é o de que se os animais que são mortos nessas condições (ideais) sejam, portanto, substituídos por outros animais que, por sua vez, terão uma vida tão ou mais prazerosa e satisfatória quanto tinha o animal que foi morto para que outro viesse a existir. $\mathrm{O}$ argumento da substituição se baseia numa ideia de rotatividade na criação de animais. Então, de acordo Llorente,

Não temos qualquer base para criticar esta prática do ponto de vista utilitarista: a utilidade que seria, por outro lado, perdida quando o animal é morto, é produzida, ou antes, desfrutada por um novo animal que é trazido a existência para substituílo (LLORENTE, 2009, p. 70, tradução nossa).

Agindo deste modo, isto é, substituindo o animal morto por um novo que é trazido à existência, "não há uma perda total da utilidade" (LLORENTE, p. 70, tradução nossa), pois se por um lado um animal perde o prazer de desfrutar a vida, o novo que passa a existir em seu lugar compensa essa perda pelo prazer que experimentará. Para Llorente, o ponto de vista do utilitarismo hedonista sustenta que o prazer desfrutado pelos seres humanos ao consumirem a carne dos animais abatidos nessas circunstâncias, representa, também, um modo favorável de aumentar o prazer em geral, isto é, tanto para os animais que desfrutaram o prazer de serem trazidos à existência, quanto aos humanos que desfrutaram de comê-los. Isso implica, portanto, que:

Se adotarmos o utilitarismo, então temos uma obrigação de comer carne. Este é um modo de maximizar a utilidade a este respeito, e todos os interessados, animais e humanos, do mesmo modo se beneficiariam (LLORENTE, 2009, p. 70, tradução nossa). 
Singer reconhece, não apenas na segunda edição de Libertação Animal, mas também em Ética Prática, que este argumento levanta fortes objeções teóricas à defesa moral do vegetarianismo, e para o qual ele ainda não encontrou uma solução que dê conta de maneira plenamente satisfatória de todas as implicações, dificuldades e dilemas que o argumento impõe. ${ }^{11}$ A revisão desse argumento é a mudança filosófica mais significativa em Libertação Animal, quando, em sua primeira edição, Singer considerava tal argumento absurdo, pois precisaríamos justificar a possibilidade de beneficiar um ser que nem sequer existe. Já na segunda edição sua mudança de opinião repousa sobre a seguinte consideração:

[...] a maioria de nós concordaria que seria errado trazer uma criança ao mundo se soubéssemos, antes de ela ser concebida, que teria um defeito genético que tornaria sua vida breve e infeliz. Conceber uma criança assim é causar-lhe um mal. Portanto, podemos realmente negar que trazer ao mundo um ser que terá uma vida agradável é conferir a esse ser um benefício? Para negar isso, teríamos de explicar por que os dois casos são diferentes e não consigo encontrar uma maneira satisfatória de fazer isso (SINGER, 2004, p. 259).

Quanto ao argumento da substituição analisado mais amplamente em Ética Prática, Singer observa que para os animais que podem conceber a si mesmos como seres distintos no passado e no futuro, há uma "razão direta para não matá-los, uma razão cuja força varia na mesma medida em que o animal seja capaz de ter desejos para o futuro" (SINGER, 2018, p. 185). Com esse raciocínio, concede o benefício da dúvida a uma grande variedade de animais.Em relação aos animais que não são autoconscientes, Singer argumenta que a razão direta para não matá-los se dá pela perda de uma vida agradável ou desfrutável, de modo que se a vida não era agradável, nenhum erro foi cometido. Mas, ainda que esse animal pudesse ter uma vida agradável é discutível afirmar que nenhum erro é cometido, ainda que em decorrência da vida retirada, esse animal morto seja substituído por outro que leve uma vida igualmente prazerosa. Isso porque, pondera o autor, "adotar esse ponto de vista implica sustentar que um erro praticado contra um ser vivo pode ser compensado por um benefício conferido a um ser até então não existente" (SINGER, 2018, p. 186). Desse modo, Singer considera que o argumento da substituição tem aplicação limitada, apesar de bem fundado enquanto raciocínio teórico de nível crítico-moral ${ }^{12}$, em um nível intuitivo e prático ele "é incapaz de justificar as fazendas industriais, onde os animais não levam vidas agradáveis e, em circunstâncias normais, tampouco justifica o abate de animais selvagens" (SINGER, 2018, p. 187).

Além disso, uma análise mais ampla do argumento da substituição também não pode, como faz Llorente, ser dissociada de sua relação com o conceito de pessoa. Singer faz uso desse conceito conforme fundamentado por Joseph Fletcher, cujas características que o constituem são: "autoconsciência, autocontrole, senso de futuro e passado, capacidade de se relacionar com os outros, preocupação com os outros, comunicação e curiosidade" (SINGER, 2018, p. 121). Essas são propriedades que estando presentes um ser, seja ele humano ou não, o coloca no status moral de pessoa. Deste modo, levando em conta essa conceitualização, se verifica que os animais comumente utilizados para alimentação humana, inclusive peixes e aves, são autoconscientes e se encaixam no conceito de pessoa, de modo que o argumento da substituição não se aplicaria aos seres dessa categoria.

Mas, embora em Libertação Animal Singer também não use o termo pessoa, pode-se perceber, no entanto, que o autor leva em conta as características que compõe o conceito de pessoa conforme conceitualizado posteriormente em Ética Prática e 
aplicado aos animais. Isso se deve, como já afirmamos, ao objetivo de Singer em escrever um livro voltado ao público em geral.

$\mathrm{O}$ argumento que ora consideramos levanta a questão de ser ou não errado matar [...]. Se um ser consegue ter desejos para o futuro, deve haver algo particularmente errado em matá-lo, algo que não é compensado pela criação de outro ser. A real dificuldade surge quando consideramos seres que não são capazes de ter desejos para o futuro - seres que podemos conceber como vivendo momento a momento, não tendo uma existência mental continua. Mesmo nesse caso, matar ainda parece ser algo repugnante. $\mathrm{O}$ animal luta contra uma ameaça à sua vida, mesmo que não compreenda que tem "uma vida", no sentido que exige a compreensão do sentido do que é existir por um determinado tempo. Mas, na ausência de alguma forma de continuidade mental, não é fácil explicar por que o dano para o animal morto não é, desde um ponto de vista imparcial, compensado pela criação de um novo animal que teve uma vida igualmente agradável (SINGER, 2004, p. 260).

No entanto, Singer reconhece que apesar de todas as dificuldades teóricas que essa questão coloca, importa analisá-la também em um nível prático, e, neste ponto, as dificuldades da questão o levam a adotar uma perspectiva mais prudente através do benefício da dúvida. Do ponto de vista prático "seria melhor que se estabelecesse como simples princípio geral evitar a morte de animais para se obter comida, exceto quando absolutamente necessário para a sobrevivência" (SINGER, 2004, p. 260), o que, segundo Singer, não configura o caso das sociedades modernas industriais. Mas, para Llorente, essa prudência de Singer com o benefício da dúvida é fortemente baseada em um princípio da não-maleficência. E, adotar como princípio geral a abstinência de atos que provoquem qualquer tipo de dano evita o tipo de problema que o utilitarismo enfrenta com o argumento da substituição. Essa parece ser a essa posição que, segundo Llorente Singer acaba recorrendo.

Percebe-se, contudo, que na última edição de Ética Prática, Singer debate a questão em termos claramente utilitaristas:

Não há dúvida de que o utilitarismo preferencial é uma forma de maximizar o utilitarismo, no sentido de que nos leva a maximar a satisfação das preferências, mas isso não significa que devamos considerar a frustração das preferências existentes como algo que possa ter sua importância diminuída pela criação de novas preferências - nos seres que já existem ou no seres que ainda vamos trazer à vida - que serão satisfeitas em seguida (SINGER, 2018, p. 176).

Singer também analisa outras implicações do argumento da substituição que o mantém vinculado ao caráter consequencialista do seu utilitarismo. Se for uma ação correta (ou um dever) trazer animais à existência em razão do prazer (utilidade) que isso irá gerar, é de presumir, portanto, que: "sendo as demais condições iguais, também deveríamos trazer à existência tantos seres humanos quanto possível" (SINGER, 2004, p. 261). Sendo assim, presumindo neste argumento que a vida dos humanos é sempre mais importante ou valiosa que a dos animais ${ }^{13}$, como afirmam os críticos de Singer, é de se considerar que deveriam existir, portanto, mais humanos do que animais. Assim, se invertermos o argumento, concluiríamos que uma maior quantidade de seres humanos poderia ser alimentada se não tivéssemos que alimentar os mais de 50 bilhões de animais terrestres mortos anualmente apenas para o consumo. Deste modo, Singer observa que a consequência do argumento "é, afinal, que os seres humanos deveriam se tornar vegetarianos" (SINGER, 2004, p. 261), uma vez que assim seria possível trazer mais humanos para a existência. Esse é outro argumento de Singer cujas características 
se aproximam muito mais do utilitarismo do que o do princípio da não-maleficência.

Por outro lado, o modo como o argumento acima se apresenta parece deixar claro que temos um dever de maximizar o prazer ou a felicidade através da criação do maior número de seres possíveis. Se for considerado que o prazer de humanos é mais complexo, com uma maior variedade e possibilidades de realização, tornando-o, assim, mais importante do que o de animais, consequentemente é o prazer de humanos que deve ser maximizado. Deste modo, tanto o argumento da substituição, quanto a resposta de Singer a ele conduzem, portanto, a autorizar que animais sejam mortos.

Mas, de acordo com Llorente, a partir do instante em que se passa a ler estes argumentos tendo em mente o princípio da não-maleficência e não o utilitarismo, $a$ morte de animais não fica autorizada com base no argumento da substituição, uma vez que, conforme entende Llorente, o princípio da não-maleficência não exige essa maximização do prazer ou felicidade, tal como ocorre com o utilitarismo, mas, antes, seu valor repousa em não causar danos (aos seres já existentes). Sendo assim, interpretando os argumentos de Singer a partir do princípio da não-maleficência, a substituição deixa de fazer sentido. Nas suas palavras:

Se procedermos, corretamente, da premissa de que a posição desenvolvida em Libertação Animal está baseada no principio da não-maleficência e não no utilitarismo, o argumento da substituição dificilmente pode ser usado para criticar a visão de Singer em seu livro, especialmente se tivermos em mente que o principio de não- maleficência não requer qualquer dever de maximização (LLORENTE, 2009, p. 72, tradução nossa).

Conforme entende Llorente, diferentemente do princípio utilitarista,

O princípio da não-maleficência, por outro lado, serve para fundamentar a condenação de matar animais para alimento na maioria das circunstâncias pela simples razão de que a finalidade da vida de um animal será, de um modo geral, para lhe causar dano.(LLORENTE, 2009, p. 72, tradução nossa).

Ainda que Llorente traga algumas evidências de que Libertação Animal contém argumentos que se assemelham ao princípio da não-maleficência e que assim interpretada a obra seria o suficiente para evitar alguns problemas, como o da substituição, devemos analisar até que ponto o autor não estaria insistindo em uma interpretação equivocada para resolver um único problema e ignorando todos os outros que o utilitarismo resolve de maneira mais satisfatória do que o próprio princípio da não-maleficência. Em alguns casos, seguir de maneira absoluta o princípio de não causar danos pode resultar em prejuízos muito maiores, como é o caso do terrorismo. Além disso, embora haja alguns argumentos que se aproximem do princípio da nãomaleficência, isso, por sua vez, não faz desaparecer os aspectos utilitaristas de Libertação Animal e da posição filosófica central do pensamento de Singer como um todo. Deve-se levar em conta, principalmente, o modo como os argumentos estreitamente vinculados ao utilitarismo quando Singer os repete e os aprofunda em Ética Prática, cuja escrita, por sua vez, tem um caráter mais técnico-acadêmico em razão do público a que foi destinada.

Por fim, há de se considerar que o princípio da não-maleficência contém, em si, um aspecto utilitarista, ao menos um utilitarismo negativo, na medida em que não causar dano se justifica por motivos utilitaristas, em razão de que não produzir dor, sofrimento e infelicidade possui um valor positivo para a felicidade. Como observa Dall'Agnol:

O utilitarismo sustenta que a felicidade é o maior bem que podemos alcançar e 
que as ações são moralmente corretas ou não na medida em que são meios adequados para atingir esse fim último. Como podemos perceber, há uma proximidade grande entre o princípio bioético da beneficência, estudado no primeiro capítulo e o utilitarismo. Mais do que isso, o utilitarismo engloba, no seu princípio fundamental, tanto os deveres de beneficência quanto da nãomaleficência (DALL'AGNOL, 2004, p. 64, grifo nosso).

Sendo assim, identificar o princípio da não-maleficência no argumento de Singer em Libertação Animal não exclui ou não anula o seu aspecto utilitarista, mas, ao contrário, o afirma na medida em que o princípio de não causar dano está implícito no preceito moral utilitarista.

\section{A JUSTIFICAÇÃO ÉTICA PARA O VEGETARIANISMO E O ARGUMENTO DA INEFICIÊNCIA.}

O terceiro ponto analisado por Llorente diz respeito às prescrições morais que se derivam da argumentação de Singer em Libertação Animal. A principal envolve diretamente a responsabilidade pelas ações que fazemos na nossa vida "tornando-a o mais isenta de crueldade que pudermos" (SINGER, 2004, p. 180). De acordo com Singer, segue-se que "observar o princípio da igual consideração de interesses exigenos sermos vegetarianos. Este é o passo mais importante" (SINGER, 2004, p. 263). ${ }^{14}$ A partir desse principio deve ser reconhecida "a necessidade moral de recusar comprar ou comer a carne ou outros produtos de animais que têm sido criados nas condições das modernas fazendas industriais" (SINGER, 2004, p. 193). Do ponto de vista ético, isto é o mínimo que deve ser feito ao se levar em consideração os interesses animais.

Ao analisar essa prescrição moral utilitarista do vegetarianismo como uma ação prática e eficaz para cumprir o objetivo de diminuir o sofrimento e a morte de animais, Llorente coloca em discussão o que denominamos, aqui neste artigo, de argumento da ineficiência. Muitos críticos argumentam que o fato de uma pessoa decidir abster-se de comprar e comer carne é ineficiente para gerar algum efeito, principalmente para os animais que já estão destinados ao abate e consumo. De fato, Singer reconhece que um ato isolado não pode gerar um efeito significativo e direto sobre evitar o sofrimento e a morte de animais. No entanto, em resposta a tais críticas, ele considera que a prática por uma grande parte de consumidores pode ter algum impacto em relação aos animais criados e abatidos. Ou seja, há um nível que quando alcançado, terá em um longo prazo um efeito significativo.

Mas, em relação a níveis individuais, isto é, no que diz respeito ao que uma única pessoa pode fazer, Llorente compreende que o argumento para o vegetarianismo não precisa estar baseado no utilitarismo ou em seus cálculos que podem ser, de um ponto de vista quantitativos ineficientes ou desfavoráveis na preservação do sofrimento de animais. Para Llorente, o princípio da não-maleficência evitaria a crítica da ineficiência que o fundamento utilitarista para o vegetarianismo sofre, pois a quantidade não tem um peso moral como o tem para o utilitarismo. A prescrição moral de não causar dano, por si só, já é suficiente para fundamentar o dever moral vegetarianismo sem precisar levar em conta sua eficiência ou ineficiência quantitativa. Mas, de que modo mais precisamente o princípio da não-maleficência se mostra mais consistente com a prescrição moral do vegetarianismo, evitando esse e os outros problemas do utilitarismo até aqui analisados?

De acordo com os bioeticistas Beauchamp e Childress, o princípio da nãomaleficência "determina a obrigação de não infligir dano intencionalmente" (BEAUCHAMP \& CHILDRESS, 2002, p. 150), compreendendo que dano significa, 
entre outras coisas, causar algum tipo de prejuízo físico e psicológico, dor, incapacidade, sofrimento, e morte. Para os autores, no entanto, princípio da nãomaleficência se amplia e fundamenta uma série de regras morais que norteiam as ações. As principais são: "1) Não matar. 2) Não cause dor ou sofrimento a outros. 3) Não causar incapacitação a outros. 4) Não causar ofensa a outros. 5) Não despojar outros dos prazeres da vida. (BEAUCHAMP \& CHILDRESS, 2002, p. 214)"15. Pensando, portanto, nas razões para justificar o vegetarianismo a partir dessas prescrições derivadas do princípio da não-maleficiência, fica evidente que:

A prática de comer carne claramente causa dano aos animais criados para consumo humano (por caracteristicamente privá-los de uma vida decente durante suas vidas e, basicamente, por privá-los da vida em si), um agente deve abster-se da prática de comer carne (LLORENTE, 2009, p. 73, tradução nossa).

O prejuízo causado para um único ser, neste caso, um animal, já configura um dano cujo um erro moral que ele implica deve ser evitado. Novamente, aqui, o princípio da não-maleficência se mostra como uma expressão utilitarista, na medida em que não causar dano é um modo de não produzir dor e infelicidade. Como já observamos, o utilitarismo considera que abster-se de atos que provoquem danos é um ato moralmente correto. Então, interpretar a teoria de Singer como derivada do princípio da nãomaleficência não parece representar uma melhoria no argumento pelo vegetarianismo, porque as conclusões de Llorente decorrem justamente de um raciocínio que carrega em si aspectos utilitaristas: a abstenção da prática de comer carne se justifica pelo dano causado ao animal, ou seja, pensa-se na consequência possível do ato, no dano, o que significa ponderar os interesses envolvidos. Neste caso, não causar dano é uma escolha moral que satisfaz a preferência ou o interesse em não sofrer.

Em suma, tendo em vista essas questões, pouca ou nenhuma diferença substancial há, nesse aspecto, entre o utilitarismo, seja ele o preferencial ou o hedonista e o princípio da não-maleficência conforme sustentado por Llorente.

\section{INTERVENÇÃO NA NATUREZA}

A quarta questão analisada por Llorente diz respeito à intervenção humana na natureza com a finalidade de prevenir os danos que os animais infligem uns nos outros. Essa ação tem o objetivo, por exemplo, de impedir o "dano" que um leão (predador) causa na zebra (presa) em um habitat natural. Os princípios normativos do utilitarismo originam o seguinte problema: se o utilitarismo tem como finalidade diminuir a dor e maximizar o prazer, seria correto, portanto, interferir na natureza para prevenir que um animal cause dor ou mate outro animal a fim de reduzir quantidade total de sofrimento existente entre os animais? É justamente essa dificuldade que Llorente atribui à Libertação Animal quando interpretada na perspectiva utilitarista, pois coloca sob o utilitarismo a responsabilidade de uma interferir maciçamente na natureza e na vida dos animais como um todo.

Singer reconhece que "temos de admitir que a existência de animais carnívoros impõe um problema à ética do movimento de Libertação Animal, qual seja, se temos de fazer algo com relação a isso" (SINGER, 2004, p. 256). Uma implicação desse problema poderia significar, por exemplo, no dever de eliminar espécies carnívoras da natureza ou se possível modificá-las geneticamente para deixarem de serem predadoras e necessitarem de carne para sobreviver. Mas, de um modo mais amplo, Singer considera que o melhor é intervir o menos possível na forma de vida dos animais, com 
exceção de casos muito específicos.

Por outro lado, Singer reconhece que em muitos casos, não diretamente vinculado com a perspectiva de ações mencionadas anteriormente, a interferência humana na natureza e nos animais é benéfica e moralmente aceitável. É o caso de quando é possível melhorar as condições de vida dos animais em situações muito específicas, como, por exemplo, de animais marinhos encalhados nas praias ou a manutenção e ampliação de reservas naturais destinadas à preservação da vida selvagem etc. Tais atos se mostram justificáveis e até mesmo possíveis, pois eles preservam e salvam a vida pela manutenção e conservação dos ecossistemas e não na alteração direta da própria peculiaridade ou forma de vida animal.

Mas, quanto à questão específica de se eliminar as espécies carnívoras, ou ainda promover sua alteração genética para modificar o instinto predatório e a necessidade bioquímica de carne em animais carnívoros, Singer sustenta que não deveríamos realizar tais tipos de interferências, pois, com base nas experiências do passado, verifica-se que em um longo prazo as interferências na natureza têm causado mais prejuízos ao invés de benefícios. Tal concepção tem uma perspectiva utilitarista consequencialista.

[...] a julgar pelos registros do passado, qualquer tentativa de mudar ecossistemas em grande escala está fadada a fazer mais mal do que bem. Por essa razão, senão por outra, é verdadeiro afirmar que, exceto em alguns pouquíssimos e limitados casos, não podemos nem devemos tentar regulamentar a natureza. Teremos feito o bastante se eliminarmos a desnecessária matança e crueldade que nós próprios praticamos contra outros animais (SINGER, 2004, p. 257).

Esse problema da intervenção levanta outra objeção que se assemelha ao argumento da substituição. Pode-se argumentar que ao criarmos animais para o consumo estamos conferindo a eles uma vida muito melhor se comparada com a vida que teriam em um ambiente selvagem, no qual os animais caçam e matam uns aos outros. Por isso, por pior que sejam as condições nas fazendas industriais modernas, ainda assim elas não são piores do que os constantes riscos e ameaças que a própria natureza impõe, como a fome, o frio, a dor, a ameaça e a exposição aos predadores. Levando isso em conta, portanto, não deveríamos fazer objeções ao modo como os animais são tratados nas indústrias. Ainda que sejam ruins, não são piores do que na natureza.

Primeiramente, deve-se levar em consideração que abster-se de criar e manter um animal confinado em uma fazenda industrial, não implica, necessariamente, que ele terá uma vida no ambiente natural. Muito provavelmente, se parássemos de trazer esses animais à existência dentro das modernas fábricas de criação, eles não passariam a existir na natureza. Isso porque, os animais de consumo não são animais silvestres, mas domésticos, ou seja, já são sistematicamente manejados e transformados zootecnicamente, distinguindo-se da espécie que o originou. Nesse sentido, é uma ingenuidade comparar a vida destes animais na indústria com uma existência na natureza. Eles não são adaptados para outra forma de vida. Assim:

A extinção das granjas industriais não significa um retorno à vida selvagem dos animais ali criados. Os animais que vivem nas granjas industriais hoje forma criados por seres humanos para crescer nesses lugares e ser vendidos como comida (SINGER, 2004, p. 258).

Embora a vida em confinamento possa tirar os animais de situações como frio, escassez de alimentos e a predação, isso não significa que serão mais bem tratados em fazendas de criação, onde, por outro lado, estão sujeitos a inúmeros outros tipos de 
danos que são inexistentes numa vida natural. No sistema de confinamento, os animais são mortos muito mais prematuramente e sem a chance de fuga ou proteção dos seus progenitores para a sobrevivência, como ocorre na vida selvagem e livre. Pensada dessa maneira, nota-se que a comparação entre as duas condições de vida não se mostra favorável a uma defesa da criação e consumo de animais e, portanto, este tipo de intervenção na natureza, ou mais precisamente na vida dos animais não torna, necessariamente, suas vidas melhores.

Mas, segundo Llorente, o que é importante pensarmos nesses casos é que "se nós procedermos do princípio da não-maleficência não precisamos nos preocupar com esses tipos de deliberações (LLORENTE, 2009, p. 75, tradução nossa)" e nem mesmo precisamos admitir, como faz Singer, que a existência de animais carnívoros coloca certos tipos de problemas para a Libertação Animal, uma vez que o princípio da nãomaleficência, exige que nos abstenhamos de praticar atos danosos sem nos obrigar a buscarmos maximizar o bem. Deste modo, o problema da interferência na vida animal deixa de fazer sentido, uma vez que a maximização do prazer não é um dever moral como o é para o utilitarismo.

Porém, Llorente ignora, pelas razões que expusemos acima, que Singer faz a objeção à intervenção na natureza a partir de um cálculo utilitarista, isto é, levando em conta que as consequências seriam piores e que interfeririam diretamente no interesse dos animais, e baseando-se, sobretudo, numa perspectiva, segundo a qual devemos interferir o menos possível na vida natural. Singer excepciona, contudo, que alguns pouquíssimos e limitados casos podem justificar essa intervenção, mas essa conclusão só se apresenta mediante um cálculo utilitário.

Em outras palavras, estas escolhas, segundo Singer, resultam, mais precisamente, em danos do que em benefícios, e ainda que tal posição ética possa ter características baseadas no princípio da não-maleficência, isto não deixa de ser uma interpretação utilitarista e consequencialista a respeito das tomadas de decisões, escolhas e ações. Se, como temos sustentado ao longo deste artigo, o princípio da nãomaleficência chega a resultado semelhante, isso se deve justamente porque os princípios do utilitarismo fundamentam e se estendem, também, aos chamados deveres da não-maleficência. Logo, não há, como busca sustentar Llorente, uma máinterpretação ao se atribuir uma perspectiva utilitarista em Libertação Animal.

\section{ESPECISMO}

Além da crítica anterior de que Libertação Animal mantém posições especistas, há ainda outra inconsistência relacionada a essa questão quando a obra é interpretada a partir de uma perspectiva utilitarista. Para o utilitarismo, as ações não possuem valor intrínseco, mas antes, um valor instrumental, isto é, servem para algum fim, que se encerra em maximizar o prazer e a felicidade. Isso implica, segundo Llorente que:

[...] se um agente utilitarista sabe que um dado ato especista maximizará a utilidade, eles estariam sobre uma obrigação de realizar o ato, isto é, seria moralmente exigido agir de um modo especista. Deste modo, um utilitarista não pode condenar categoricamente o especismo (LLORENTE, 2009, p. 75, tradução nossa).

Assim, compreende-se que: "se o princípio que orienta e regula nosso tratamento dos animais é "não cause dano" e não temos assumido qualquer dever de maximizar o bem [...] nós podemos, sem qualquer risco de contradição condenar categoricamente o especismo (LLORENTE, 2009, p. 76, tradução nossa)". Tomando o especismo como 
uma injustificada forma de discriminação, por ser caracterizado como uma atitude em favor dos interesses dos membros de uma espécie contra os membros de outra espécie, e analisando-o na perspectiva da não-maleficência, Llorente considera que: "se surgir uma situação em que uma ação especista servirá para maximizar o bem, o fato de que ela também causaria danos seria motivo suficiente para o agente se abster de praticar o ato (LLORENTE, 2009, p. 76, tradução nossa), o que não seria o caso exigido pelo utilitarismo.

No entanto, os potenciais danos causados pelas ações do agente moral sobre o paciente moral são considerados no cálculo de utilidade, embora o raciocínio de Llorete pareça não levar isso em conta. Por tal razão, Singer enfatiza que, se desse cálculo utilitário surgir um "conflito irreconciliável entre as necessidades básicas para a sobrevivência de animais e seres humanos normais, não é especismo dar prioridade à vida daqueles que têm noção biográfica de sua própria existência e uma orientação muito mais forte para o futuro" (SINGER, 2018, p. 189). Desse modo, interpretar a teoria como derivada de um princípio da não-maleficência, nesse caso, não eliminaria o conflito irreconciliável de outra maneira senão à utilitária.

O fato é que o cálculo utilitarista leva em igual consideração os interesses de todos os envolvidos, o que parece levar à consequências práticas muito semelhantes aos do princípio da não-maleficência, mas com a vantagem de apurar as consequência mediante cálculos que potencialmente podem levar a um resultado mais justo. Para isso, o princípio da igual consideração de interesses pressupõe um cuidado ao compararmos os interesses de diferentes espécies, além de priorizar o alívio do sofrimento maior. A menor capacidade racional dos animais pode fazer com que sofram menos ou mais, dependendo da situação, e isso é de relevante na ética de Singer. Sendo assim, em tese, seria possível Singer defender uma ação especista em um caso hipotético muito específico, mas, o mesmo se poderia dizer de outras formas de preconceito que o autor igualmente considera indefensáveis. $\mathrm{O}$ cálculo de utilidade, contudo, precisa considerar esses fatores a fim de evitar consequências que ensejem ações especistas ou estimulem outras formas de preconceito, pois só assim pode efetivamente minimizar sofrimento futuro. As situações, portanto, são muito mais complexas do que parece pressupor a interpretação de Llorente.

\section{Conclusão}

Ao longo deste trabalho, nos propomos em analisar a interpretação trazida por Llorente de que a obra Libertação Animal, diferentemente do que se costuma afirmar, não tem sua estrutura moral baseada no utilitarismo. Antes, a perspectiva ética que a fundamenta é o princípio da não-maleficência, que pode ser resumido pela sentença não causar danos. De fato, como analisamos neste artigo, em Libertação Animal Singer não faz uso de termos rigorosamente filosóficos e conceitualizados do princípio do utilitarismo. $\mathrm{O}$ mesmo, no entanto, também se dá em relação ao princípio da nãomaleficência. Isso se justifica em razão dessa obra não ser dirigida ao público acadêmico. Tampouco Singer se propõe a fazer nela uma fundamentação filosófica do utilitarismo, tal como é feito em Ética Prática. Porém, o fato de não mencionar diretamente esses conceitos filosóficos utilitaristas não anula as características dessa corrente ética em sua obra. A ausência direta de menções ao utilitarismo não é uma forte evidência, como Llorente busca inflar, de que Singer não fundamenta sua obra nessa perspectiva. Diferentemente de Llorente, demonstramos que as similaridades de Libertação Animal com outras obras e artigos de Singer, principalmente Ética Prática, 
devem, seguramente, ser levadas em conta ao se analisar criticamente a estrutura moral em Libertação Animal. Llorente não considera o pensamento filosófico de Singer como um todo, mas o restringe apenas em analisar a partir de uma obra cuja intenção não era, de fato, ser filosófica. Um pensamento filosófico deve ser analisado a partir de um conjunto de escritos do autor e não somente a partir de uma obra. Quando analisado em conjunto e observando as similaridades entre as obras, as críticas de Llorente se enfraquecem.

Além disso, o presente artigo expressou de que modo Llorente ignora o fato de Singer fundamentar as diversas posições que defende e reflete, a partir do utilitarismo. Sua concepção sobre a ética em relação aos animais não seria, portanto, especialmente diferente. Se assim o fosse, Llorente teria de sustentar, então, que Ética Prática, que contém profundas semelhanças com Libertação Animal, estaria, por sua vez, baseada no princípio da não-maleficência, o que é claramente insustentável.

Além dessas e outras críticas à interpretação de Llorente, analisamos, também, de que modo o próprio princípio da não-maleficência que o autor insiste em atribuir à Libertação Animal é um princípio cujas características o aproximam significativamente de uma fundamentação utilitarista. Como analisamos, não causar dano é um ato que se justifica por razões utilitaristas, no mínimo em um utilitarismo negativo, uma vez que isso evita que um ser venha a sofrer dor, desprazer e infelicidade. Os deveres originados do princípio da não-maleficência são englobados pelos deveres que o utilitarismo origina. Deste modo, ainda que existam razões para se afirmar que Libertação Animal possui a estrutura moral fundamentada no princípio da não-maleficência, isso, por sua vez, ainda repousa em bases fortemente utilitaristas. Por essa razão, inclusive, notamos que o problema do especismo não é eliminado, como pretende Llorente, quando a teoria é interpretada como derivada de um princípio da não-maleficência. Ora, se os danos eventualmente causados por uma ação especista são considerados suficientes para que o agente se abstenha de praticá-la, essa conclusão se fundamenta em uma perspectiva utilitarista, ainda que em sua forma negativa.

Como podemos ter observado neste trabalho, as questões analisadas por Singer são muito mais amplas e complexas do que o modo reducionista e simplista pelo qual Llorente as expõem, analisa e as critica. Sua interpretação se mostra limitada por se restringir a pequenos trechos do conjunto de reflexões feitas por Singer em diversas obras e artigos. Esse método adotado por Llorente acabou por fragmentar a visão do todo que o autor deveria ter da obra e do pensamento ético de Singer, levando em conta, principalmente, as similaridades de Libertação Animal com muitos outros textos utilitaristas de Singer, que são muito maiores do que eventuais diferenças, que basicamente se devem a um estilo de escrita e limitação de temas discutidos.

Deste modo, ao analisarmos as questões de um ponto de vista mais completo, podemos perceber que não há outra perspectiva filosófica mais presente na referida obra de Singer do que o utilitarismo. Mas, ainda que haja, como seria o caso do princípio da não-maleficência, isso ainda se mostra amparado por uma perspectiva utilitarista. Este artigo espera ter contribuído para uma reflexão mais ampla das questões aqui levantadas.

\section{REFERÊNCIAS}

BEAUCHAMP, Tom; CHILDRESS, James. Princípios de Ética Biomédica. Tradução de Luciana Pudenzi. São Paulo: Edições Loyola, 2002.

BENTHAN, Jeremy. Uma Introdução aos Princípios da Moral e da Legislação. 
Tradução de Luiz João Baraúna. 3a. Ed. São Paulo: Abril Cultural, 1984.

CRISP, Roger. Utilitarianism and Vegetarianism. In: Ethical Issues: perspective for Canadians. Ed. Eldon Soifer. Peterborough, Ontario, Broadway Press, 1997.

DALL'AGNOL. Darlei. Bioética: princípios morais e aplicações. Rio de Janeiro: DP\&A Editora, 2004.

LLORENTE, Renzo. The Moral Framework of Peter Singer's Animal Liberation: an alternative to utilitarianism. In: Ethical Perspectives, V. 16, N. 01, p. 6180, 2009.

McGINN, Colin. Our Duties to Animals and the Poor. In: Singer and His Critics.

Ed. Dale Jamieson. Oxford and Maldem, MA- Blackwell, 1999, p. 150-161.

MILL, Stuart. Utilitarismo. Introdução, tradução e notas de Pedro Galvão. Porto:

Porto Editora, 2005.

SINGER, Peter. Ética Prática. Tradução de Jefferson Luiz Camargo. 4. ed. São

Paulo: Martins Fontes, 2018.

SINGER, Peter. Libertação Animal. Tradução de Marly Winckler. Revisão

Técnica de Rita Leal Paixão. Porto Alegre, São Paulo: Lugano, 2004.

SINGER, Peter. A Response. In: Singer and His Critics. Ed. Dale Jamieson.

Oxford and Maldem, MA- Blackwell, 1999. p. 269-335.

SINGER, Peter. Utilitarianism and Vegetarianism. In: Philosophy and Public Affairs, V. 9, N. 4, p. 325-337, 1980.

SOLOMON, Robert. The Expanding Circle: Compassion and the Liberation Ethic. In: Singer and His Critics. Ed. Dale Jamieson. Oxford and Maldem, MABlackwell, 1999, p. 64-84.

BEAUCHAMP, Tom; CHILDRESS, James. Princípios de Ética Biomédica. Tradução de Luciana Pudenzi. São Paulo: Edições Loyola, 2002.

BENTHAN, Jeremy. Uma Introdução aos Princípios da Moral e da Legislação. Tradução de Luiz João Baraúna. 3a. Ed. São Paulo: Abril Cultural, 1984.

CRISP, Roger. Utilitarianism and Vegetarianism. In: Ethical Issues: perspective for Canadians. Ed. Eldon Soifer. Peterborough, Ontario, Broadway Press, 1997.

DALL'AGNOL. Darlei. Bioética: princípios morais e aplicações. Rio de Janeiro: DP\&A Editora, 2004.

LLORENTE, Renzo. The Moral Framework of Peter Singer's Animal Liberation: an alternative to utilitarianism. In: Ethical Perspectives, V. 16, N. 01, p. 61-80, 2009.

McGINN, Colin. Our Duties to Animals and the Poor. In: Singer and His Critics. Ed. Dale Jamieson. Oxford and Maldem, MA- Blackwell, 1999, p. 150-161.

MILL, Stuart. Utilitarismo. Introdução, tradução e notas de Pedro Galvão. Porto: Porto Editora, 2005.

SINGER, Peter. Ética Prática. Tradução de Jefferson Luiz Camargo. 4. ed. São Paulo: Martins Fontes, 2018.

SINGER, Peter. Libertação Animal. Tradução de Marly Winckler. Revisão Técnica de Rita Leal Paixão. Porto Alegre, São Paulo: Lugano, 2004.

SINGER, Peter. A Response. In: Singer and His Critics. Ed. Dale Jamieson. Oxford and Maldem, MA- Blackwell, 1999. p. 269-335.

SINGER, Peter. Utilitarianism and Vegetarianism. In: Philosophy and Public Affairs, V. 9, N. 4, p. $325-337,1980$.

SOLOMON, Robert. The Expanding Circle: Compassion and the Liberation Ethic. In: Singer and His Critics. Ed. Dale Jamieson. Oxford and Maldem, MA- Blackwell, 1999, p. 64-84.

\section{NoTAS}

1 Singer ainda afirma que: "A ideia de que também é errado matar animais de forma indolor dá suporte adicional a algumas dessas conclusões, o que é bem-vindo, porém não 
estritamente necessário" (SINGER, 2004, p. 25). É importante levar em conta que a problemática em torno de tirar a vida é amplamente discutida nos capítulos 4 e 5 de Ética Prática e não em Libertação Animal.

2 Além dessa obra, devemos destacar ainda dois outros livros publicados mais recentemente por Peter Singer juntamente com Katarzyna De Lazari-Radek, e que tratam da ética utilitarista. The Point of View of the Universe: Sidwick and the Contemporary Ethicis, de 2014; e, Utilitarianism: a short introduction, de 2017.

3 Para uma leitura das razões utilitaristas para não ser vegetariano, Cf. CRISP, 1997. Neste artigo, Crisp defende que os utilitaristas, ainda que estejam moralmente obrigados a se absterem de comer carne de animais criados na forma industrial, teriam, por outro lado, o dever de consumir carnes de animais que não são criados de forma intensiva. Para Crisp, defendendo fortemente o argumento da substituição, considera que a utilidade seria aumentada se os animais viessem a existirem, sendo-lhes garantida uma vida satisfeita, prazerosa até o momento da morte rápida.

4 No Capítulo IV da obra Uma Introdução aos Princípios da Moral e da Legislação, Bentham desenvolveu uma "régua" para se medir a dor e o prazer segundo os critérios de: Intensidade, duração, certeza ou incerteza, proximidade no tempo (longiquidade), fecundidade, pureza e extensão (Cf. BENTHAM, 1984, p. 16-17).

5 Esse mesmo argumento aparece também no capítulo 3, Igualdade para os Animais, de Ética Prática. Boa parte deste capítulo segue a linha argumentativa de Libertação Animal, com a diferença de que o capítulo é precedido por uma fundamentação moral utilitarista nos capítulos 1 e 2 . Isso influencia a interpretação de que esta última é uma obra, do mesmo modo, utilitarista.

6 Ao final do primeiro capítulo de Ética Prática, Singer enuncia: "Este livro pode ser entendido como uma tentativa de indicar de que maneira um utilitarista preferencial coerente lidaria com uma série de problemas polêmicos" (SINGER, 2018, p. 22). É importante destacar que em sua última edição revisada desta obra, Singer se mostra mais categórico em defender o utilitarismo preferencial quando comparada com a edição anterior.

7 "Talvez chegue o dia em que o restante da criação animal venha a adquirir os direitos que jamais poderiam ter-lhe sido negados, a não ser pela mão da tirania [...] A questão não é 'Eles são capazes de raciocinar?', nem 'São capazes de falar?', mas, sim: 'Eles sã capazes de sofrer?"' (BENTHAM apud SINGER, 2004, p. 09).

8 É difícil fazer uma afirmação de que seres de espécie diferente teriam a mesma experiência ao viver situações similares. Singer observa que "seres humanos adultos normais possuem capacidades mentais que, em certas circunstâncias, os levam a sofrer mais do que sofreriam animais nas mesmas circunstâncias" (SINGER, 2004, p. 18). Diante de um experimento científico, por exemplo, um ser humano sofreria mais se comparado com um rato em razão justamente de uma percepção mais ampla de toda a situação em razão dessa maior capacidade mental: "previsão, memoria mais detalhada, maior compreensão do que está acontecendo, e assim por diante" (SINGER, 2004, p. 19). Por outro lado, a menor capacidade mental dos animais também pode ser uma razão para intensificar o sofrimento, pois o animal não é capaz de distinguir entre uma captura para salvá-lo de um dano e a captura pra mata-lo. Ambas as ações lhe são desagradáveis e aterrorizantes.

9 É importante salientarmos que Singer não está defendendo pesquisas em animais de uma maneira deliberada, como pode parecer se tomarmos a citação acima de maneira isolada e fora de um contexto argumentativo mais amplo. De um modo geral, ele está analisando que se uma pesquisa com animais pode salvar milhares de vidas humanas, como é hipotético, também aceitaríamos que se fizesse em seres humanos, por exemplo, acometidos por severas lesões cerebrais? (Cf. SINGER, 2004, p. 94-95).

10 Cf. SINGER, 2018, p. XIII.

11 Em Libertação Animal, Singer afirma: "Ainda tenho dúvidas quanto a essa questão. A proposição de que a criação de um ser de alguma forma compense a morte de outro tem algo de peculiar" (SINGER, 2004, P. 260). Na última edição de Ética Prática, Singer nota também que: "Ao revisar essas seções para esta edição, vi-me incapaz de defender, com o mínimo de confiança, que a posição assumida por mim na edição anterior - com base 
exclusivamente no utilitarismo preferencial - oferece uma resposta satisfatória a esses dilemas" (SINGER, 2018, p. XIII).

12 A partir de Hare, Singer distingue dois níveis de raciocínio moral: o intuitivo e o crítico. O raciocínio crítico considera as possíveis consequências da ação moral para maximixar a utilidade, como se faz ao analisar um caso hipotético. Mas antecipar todas essas consequências não se mostra prático na vida real, quando um conjunto de princípios intuitivos bem escolhidos pode oferecer melhores respostas. Logo, o raciocínio crítico se justificaria apenas em "circunstâncias nas quais seja absolutamente claro que, se nos afastarmos desses princípios, teremos um resultado muito melhor do que se nos prendêssemos a eles" (SINGER, 2018, p. 129).

13 Para Singer as razões pelas quais se considera errado tirar uma vida é variável e depende de determinadas características que podem ser possuídas tanto por animais quanto por humanos, variando em indivíduos de ambas as espécies. Singer critica a concepção de que a vida humana possui sempre e a priori importância maior do que a vida de um animal não humano. Sobre o conceito de pessoa e o erro de se tirar a vida, Cf. SINGER, 2018 , cap. 4 e 5.

14 Além disso, o princípio da igual consideração de interesses implica também que "devemos parar de usar outros produtos de origem animal para cuja obtenção animais forma mortos ou submetidos a sofrimentos. Não devemos usar pele. Tampouco devemos comprar produtos feitos de couro [...]" (SINGER, 2004, p. 263).

15 Deve-se ressaltar que Beuachamp \& Childress analisam o princípio da não-maleficência em sua obra de um ponto de vista humano, mais precisamente de uma ética biomédica. Nesse sentido, o dano se refere também a prejuízos em fatores que não abrangem a vida animal, como a propriedade, reputação, privacidade, com exceção, no entanto, da liberdade, que é um aspecto componente da vida animal. 